\title{
A triagem e catação de recicláveis dentro do aterro sanitário, como condicionante de vulnerabilização social de excluídos em Boa Vista-RR*
}

\section{Haroldo Scacabarossi ${ }^{1}$, Yasnara Silveira de Medeiros $^{2}$}

${ }^{1}$ Universidade Estadual de Roraima (UERR). Rua 7 de Setembro, 231. Canarinho. Boa Vista-RR (CEP 69306-530). E-mail: haroldogeo@yahoo.com.br. 2Secretaria de Educação do Estado de Roraima (SEED). Rua Barão do Rio Branco, 1495. Centro. Boa Vista-RR (CEP 69301-130).

Resumo. A triagem e a catação de recicláveis dentro do Aterro Sanitário do Município de Boa Vista, capital do Estado de Roraima estão se tornando as condicionantes principais no processo de vulnerabilização social dos já excluídos, oriundos de diversas regiões do Estado. Assim, esta pesquisa teve como objetivo apresentar o delineamento conceitual da problemática da triagem de recicláveis no Município de Boa Vista, no que diz respeito aos atores principais dos processos de catação e triagem praticados no interior do Aterro Sanitário de Boa Vista e propiciar uma discussão acerca da abordagem teórico-metodológica das variáveis dos processos, frente às recentes transformações socioambientais ligadas ao tema. As atividades ilegais de catação e triagem de recicláveis dentro de uma área pertencente ao município gera uma série de questionamentos, uma vez que o acesso ao interior do aterro é feito de forma clandestina e irregular. A problemática não está por se resolver em curto espaço de tempo, como tenta fazer o executivo municipal, entendendo que disponibilizar alternativas de melhoria na condição social e de renda para os que ali atuam seria o primeiro passo. As medidas propostas pelo Guia de Atuação Ministerial para o encerramento de lixões, enfatizadas na pesquisa, contemplam, quase em sua totalidade, as inúmeras medidas necessárias à inclusão desses trabalhadores em uma melhor condição social.

Palavras-chave: Catadores; Recicláveis; Vulnerabilização; Inclusão social.

Abstract. The recyclable scavenging and screening processes inside of the landfill as a condition of social increasing vulnerability of excluded in Boa Vista-RR. The recyclable scavenging and screening processes inside of the landfill of the Municipallity of Boa Vista, capital of the State of Roraima is turning if the main condicions in the process of social vulnerabilization of the persons already excluded, originating from several areas of the state. Thus, this research had as objective to present the conceptual delimitation of the problem of the recyclable screening in the Municipallity of Boa Vista, in what it concerns the main actors of the recyclable scavenging and screening
Recebido:

29/07/2016

Aceito:

29/09/2016

Publicado:

30/09/2016

Acesso Aberto

Artigo completo

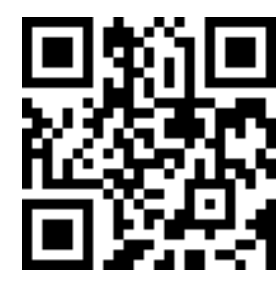

ORCID

(C) 0000-0001-9390-7020

Haroldo Scacabarossi

(1) 0000-0001-9282-5859

Yasnara Silveira de Medeiros

\footnotetext{
*Apresentado no V Congresso Brasileiro de Educação Ambiental Aplicada e Gestão Territorial, Fortaleza/CE, 8 a 11/06/2016.
} 
processes practiced inside the landfill of Boa Vista and to propitiate a discussion concerning the theoretical-methodological approach of the variables of the processeses, front to the recent environmental transformations linked to the theme. The illegal activities of recyclable scavenging and screening inside of an area belonging to the municipal district it generates several questionings, once the access to the interior of the Embankment is made in a secret and irregular way. The problem is not for solving in short space of time, as the municipal executive wants to do, understanding that to provide alternative of improvement in the social condition and of income for the ones that there act it would be the first step. The actions proposed by the Guide of Ministerial Acting for the dumping grounds closing, emphasized in the research, they meditate, almost in your totality, the countless necessary actions to those workers' inclusion in a better social condition.

Keywords: Collectors; Recyclables; Vulnerabilization; Social inclusion.

\section{Introdução}

A triagem e a catação de recicláveis dentro do Aterro Sanitário do Município de Boa Vista, capital do Estado de Roraima, estão se tornando as condicionantes principais no processo de vulnerabilização social das pessoas já excluídas do processo capitalista de produção. Assim, o presente artigo tem como objetivo apresentar o delineamento conceitual da problemática da triagem de recicláveis no Município de Boa Vista, no que diz respeito aos atores principais dos processos de catação e triagem no interior do Aterro Sanitário de Boa Vista e propiciar uma discussão acerca da abordagem teórico-metodológica das variáveis dos processos, frente às recentes transformações socioambientais ligadas ao tema.

Em primeira análise, constata-se que o Município de Boa Vista está distante de manter uma sistemática que leve em consideração aspectos sociais equânimes em relação aos catadores, bem como o cumprimento das legislações inerentes a todos os processos referentes aos Resíduos Sólidos Urbanos (RSU) gerados não são efetivados pelo executivo municipal. O mais grave nesse processo está no local de disposição final dos resíduos gerados no Município, onde o que era para ser um Aterro Sanitário controlado tornou-se um depósito de lixo a céu aberto que mais tem a ver com um lixão, contribuindo, de diversas formas, para a degradação tanto ambiental como social.

É notório que as preocupações relacionadas ao meio ambiente encontramse em destaque nas discussões, tanto na sociedade civil como no mundo acadêmico. Mas entende-se que nesse processo como um todo de alterações, modificações e impactos causados ao meio, existe o ser humano que, por alguma razão, atua naquele espaço de forma a interagir, tanto para a preservação como para o agravamento de determinadas situações e, nesse caso, sua vulnerabilização.

Se não bastassem os inúmeros equívocos causados pelo gerenciamento irracional dos RSU gerados no município, como impactos no entorno do local destinado à disposição final dos resíduos como contaminação do solo e corpos hídricos do entorno, temos a problemática dos catadores de materiais recicláveis que atuam naquele espaço, em uma atividade ilegal e desprovida de qualquer sistemática que inclua as mínimas condições de trabalho. Nesse sentido, estamos frente às chamadas discussões contemporâneas, de transformações ambientais e possibilidade de estudo do espaço geográfico com suas implicações no aspecto social. 


\section{Procedimentos metodológicos}

A pesquisa seguiu quatro etapas distintas, mas que se completaram na medida em que as atividades foram sendo concretizadas, sendo elas: a descrição do estudo, descrição da área de estudo, coleta e análise dos dados obtidos. Com base na forma de abordagem do problema, o estudo é qualitativo, pautando seus objetivos em uma pesquisa exploratória. Como procedimentos técnicos, foram utilizadas pesquisas bibliográfica e documental. A forma de coleta de dados foi transversal. Estas pesquisas têm como objetivo proporcionar maior familiaridade com 0 problema, com vistas a torná-lo mais explícito ou a constituir hipóteses. [...] $\mathrm{Na}$ maioria dos casos, essas pesquisas envolvem: (a) levantamento bibliográfico; (b) entrevistas com pessoas que tiveram experiências práticas com o problema pesquisado; e (c) análise de exemplos que estimulem a compreensão (Gil, 2002).

Com o objetivo de identificar as condições socioambientais das pessoas envolvidas no processo de gerenciamento dos RSU, manteve-se contato com os representantes de entidades que integram $o$ sistema de coleta e transporte, separação e disposição final. No Município de Boa Vista foram visitadas: a Secretaria Municipal de serviços Públicos (SMSP), Secretaria Municipal de Obras e Urbanismo (SMOU), Empresa de desenvolvimento Urbano e Habitacional (EMHUR), Secretaria Municipal de Gestão Ambiental e Assuntos Indígenas (SMGA) e a Procuradoria Geral do Município de Boa Vista (PGMU). Os órgãos estaduais visitados foram: o Ministério Público Estadual de Roraima (MPRR), Secretaria de Estado de Planejamento (SEPLAN), Centro de Geotecnologia, Cartografia e Planejamento Territorial de Roraima (CGPTERR) e a Fundação Estadual de Meio Ambiente e Recursos Hídricos de Roraima (FEMARH/RR).

No que se refere à coleta de dados estatísticos sobre o gerenciamento dos RSU, foram efetuadas visitas técnicas e entrevistas junto aos representantes de entidades prestadoras de serviços, necessárias à compreensão da organização do gerenciamento do RSU (produção, coleta, transporte e disposição final). As principais entidades foram: a Cooperativa dos Amigos, Catadores de Resíduos Sólidos do Município de Boa Vista (USSIRENDA) e na unidade de triagem Boa Esperança.

\section{O espaço geográfico}

A ação social no espaço é de fundamental importância na sociedade contemporânea, pois reflete as intervenções feitas no espaço pelo homem. Esse espaço é entendido como sendo produzido pelo homem ao longo do tempo. Segundo Santos (2002, p. 153): "O espaço deve ser considerado como um conjunto de relações realizadas através de funções e de formas que se apresentam como testemunho de uma história escrita por processos do passado e do presente". O espaço é o locus da reprodução das relações sociais de produção.

Na perspectiva crítica, a Geografia manifesta-se na postura de oposição a uma realidade social e espacial contraditória e injusta, fazendo-se do conhecimento geográfico uma arma de combate à situação existente como ponto de partida para a aproximação de seu objeto de estudo que é o espaço geográfico (Moraes, 2003). A sociedade e o espaço entendido como ciências sociais deveriam ser trabalhadas a partir de um entendimento socioespacial, considerando os conceitos-chave da geografia e o grau de parentesco, pois todos se referem à ação humana modelando e alterando a superfície terrestre de acordo com suas necessidades (Corrêa, 2000).

Nesse sentido, entende-se que o espaço escolhido para receber todo 0 resíduo sólido gerado na capital roraimense é palco de vários conflitos e perturbações, na medida em que, além de ser o espaço de sobrevivência e disputa entre as pessoas que ali atuam, travasse outro conflito com o poder público que insiste em encerrar atividade ilegal sem que sejam discutidos, de forma abrangente, todos os condicionantes de retirada de pessoas que atuam nesses espaços. 


\section{O Estado de Roraima}

O Estado de Roraima, localizado no extremo norte do Brasil, ocupa uma área de 224.301,040 km² (IBGE, 2010), distribuída entre os 15 municípios, com 450.479 habitantes e uma densidade demográfica de $2,01 \mathrm{hab} / \mathrm{km}^{2}$. Em extensão territorial, ocupa o $14^{\circ}$ lugar em relação aos outros estados da Federação.

Apresenta limites ao Norte, com a República Bolivariana da Venezuela e a República Cooperativista da Guiana; ao Sul, com o Estado do Amazonas; a leste, com a República Cooperativista da Guiana e o Estado do Pará, e a oeste, com a República Bolivariana da Venezuela e o Estado do Amazonas. O ponto exato do extremo norte do território brasileiro está localizado no Monte Caburaí e apresenta limites internacionais que se estendem por 958 km com a República Bolivariana da Venezuela e $964 \mathrm{~km}$ com a República Cooperativista da Guiana, num total de $1.922 \mathrm{~km}$ de fronteiras.

Roraima ocupa cerca de 2,6\% do território brasileiro, e 4,5\% da Amazônia Legal. Barbosa et al. (2005) afirmam que o seu espaço fitofisionômico original pode ser dividido em três grandes sistemas ecológicos como florestas, campinascampinaranas e o destaque para as savanas ou cerrados, onde se localiza a sua capital.

\section{O Município de Boa Vista}

De acordo com o IBGE (2015), Boa Vista conta com uma população estimada para 2015 de 320.714 habitantes, concentrando aproximadamente dois terços da população do Estado. Possui crescimento anual da população de 2000 a 2010 de cerca de 3,55\%, com natalidade em 2010 de 6.039 nascidos vivos e urbanização no mesmo ano de $97,71 \%$. Com relação ao Índice de Desenvolvimento Humano (IDH), dados de 2000 apontam para 0,779, e o índice de Gini de 59,36, também em 2010.

A Capital do Estado de Roraima (Figura 1) está localizada totalmente no hemisfério norte, sob as coordenadas geográficas: Latitude $2^{\circ} 49^{\prime} 11^{\prime \prime} \mathrm{N}$ e longitude $60^{\circ} 40^{\prime} 24^{\prime \prime} \mathrm{W}$ Grw, ocupando uma área de 5.687,037 $\mathrm{km}^{2}$, tendo sua instalação datada no ano de 1943. Inserida na Microrregião, Boa Vista limita-se ao Norte com o Município de Amajari; a Leste, com Bonfim e Cantá; a Oeste, com Alto Alegre e, ao Sul, com o Município de Mucajaí.

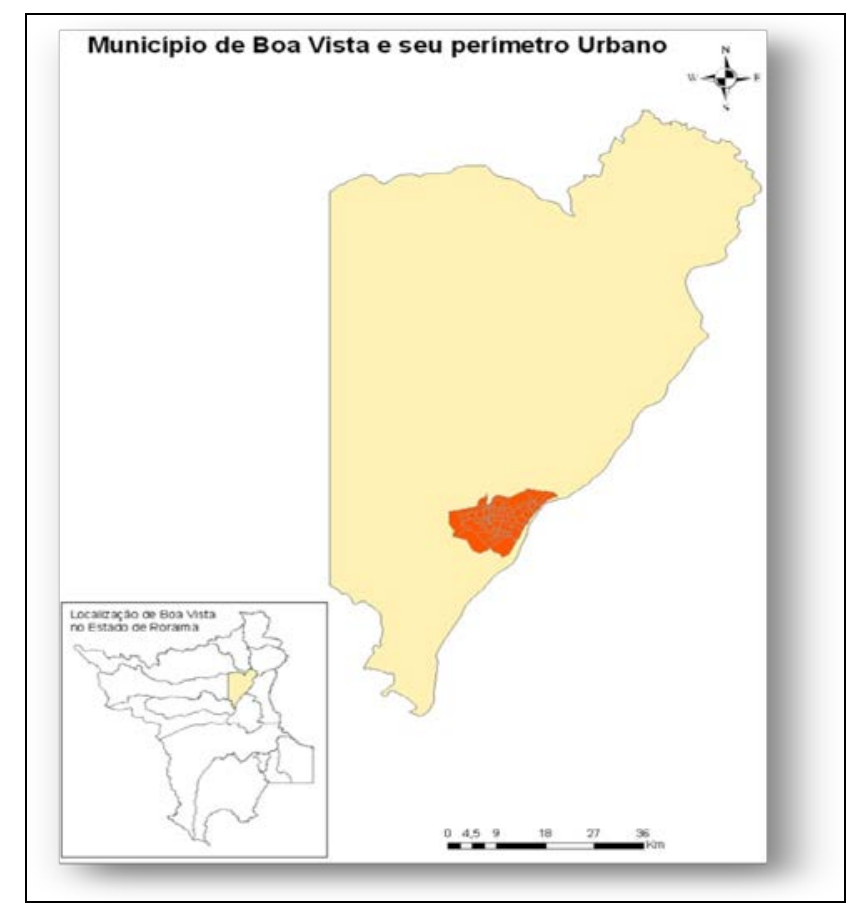

Figura 1. Município de Boa Vista e seu perímetro urbano. Fonte: Silva, 2012. 
O Município situa-se na margem direita do Rio Branco e é a única capital brasileira localizada totalmente ao Norte da linha do Equador. Apresenta-se tecnicamente bem planejada, dividida em 55 bairros (IBGE, 2010), sendo os mais populosos Pintolândia e Senador Hélio Campos, e é atualmente o núcleo polarizador do Estado. A estrutura econômica está assentada no setor terciário e, por abrigar a sede estadual, a geração de emprego é realizada, sobretudo, pelo setor público que emprega o maior contingente, vindo a seguir o setor comercial.

Está entre os municípios ressurgentes do estado e mais propícios para o agronegócio, devido ao fator de escoamento da exportação para países vizinhos como a República Bolivariana da Venezuela e República Cooperativista da Guiana, dispondo ainda da Área de Livre Comércio (ALC) e a Zona de Produtos de Exportação (ZPE), implantadas recentemente. Considerando aspectos relacionados à população e atividades econômicas desenvolvidas no Município, Boa Vista concentra $62 \%$ da população do Estado, e apresentou uma participação de 71,03\% no Produto Interno Bruto do estado no ano de 2006, contra $71,23 \%$ no ano anterior, concentrada basicamente no setor terciário (Roraima, 2009).

No que se refere aos aspectos físicos, Boa Vista está inserida em uma área plana levemente ondulada, com dissecação que varia de fraca a muito fraca, desenvolvida sobre rochas sedimentares que constituem a formação do município. Ocorrem ainda formas de acumulação (planos arenosos) e residuais subordinados (morros isolados, campo naturais e colinas isoladas), apresenta cota média de $120 \mathrm{~m}$ (Farias et al., 2013).

Ainda segundo Farias et al. (2013), Boa Vista tem na sua hidrografia a característica de estar inserida na Bacia do Rio Branco, que domina praticamente toda a área do estado e é o principal componente do sistema hidrográfico. Com o Rio Cauamé, seu principal afluente, pela margem direita do município, onde $\mathrm{o}$ regime hidrográfico da Bacia do Rio Branco é definido por um período de cheia, nos meses de março a setembro, sendo a maior enchente no mês de junho. No período seco, as águas baixam consideravelmente, impossibilitando, inclusive, a navegação no baixo Rio Branco.

\section{O Aterro Sanitário de Boa Vista}

O Aterro Sanitário do Município de

Boa Vista está localizado na área denominada Fazenda Alvorada, km 494 da BR 174, distante $10 \mathrm{~km}$ da área central do Município, com aproximadamente 94,14 hectares de área disponível para a atividade de tratamento e destinação final dos RSU gerados na capital do Estado de Roraima.

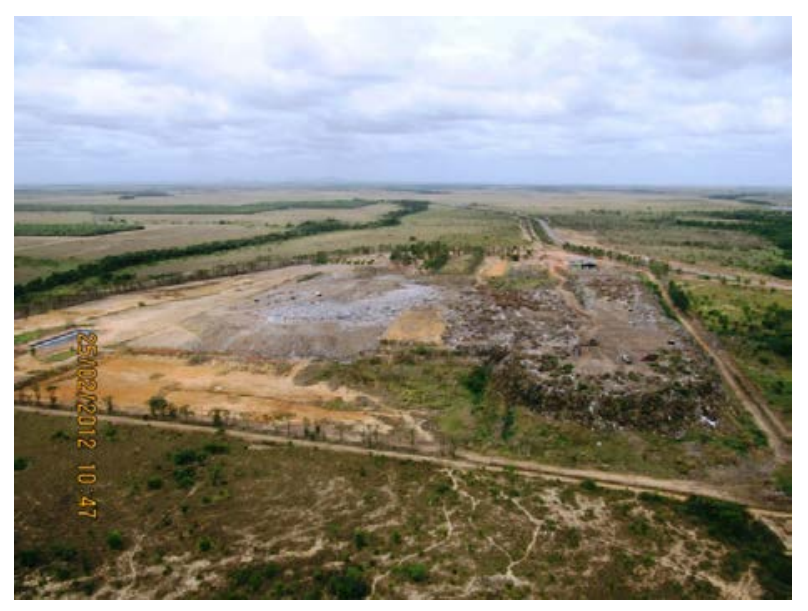

Figura 2. Aterro Sanitário do Município de Boa Vista - RR, próximo à BR 174. Fonte: Roraima (2012). 
De acordo com ABNT-NBR 8419/1984, aterro sanitário de RSU é uma técnica de disposição no solo sem causar danos à saúde pública e à sua segurança, minimizando os impactos ambientais, método que utiliza princípios de Engenharia para confinar os resíduos sólidos à menor área possível e reduzi-los ao menor volume permissível, cobrindo-os com uma camada de solo na conclusão de cada jornada de trabalho, ou a intervalos menores, se necessário.

Em relação às características e ao local onde devam ser instalados os Aterros Sanitários, a ABNT-NBR 8419/1984 diz que:

[...] as características do local destinado ao Aterro Sanitário exigem critérios básicos para a seleção como zoneamento ambiental, zoneamento urbano, acessos, vizinhança, economia de transporte, economia operacional do aterro sanitário, infraestrutura urbana, bacia e sub-bacia hidrográfica onde o Aterro Sanitário se localizará. Deve ainda ser apresentado um levantamento planialtimétrico, em escala não inferior a 1:2000, com indicação da área do Aterro Sanitário e sua vizinhança, identificando os pontos geográficos conhecidos, tais como ruas, estradas, ferrovias, rios e mananciais de abastecimento (ABNT, 1984).

O projeto inicial foi concebido e dimensionado para conter seis células dimensionadas para uma vida útil de, pelo menos, 20 anos. No local também estava prevista a construção de cercas com estacas de concreto armado e tela metálica com a função principal de evitar o ingresso no local de catadores, animais e elementos estranhos à atividade.

A área licenciada, previamente por 60 dias, no mês de junho do ano de 2000, autorizada pela Prefeitura Municipal de Boa Vista (PMBV), por meio da Secretaria Municipal de Planejamento e Meio Ambiente, Departamento Municipal de Meio Ambiente (DEMMA), que emitiu a Autorização Prévia $n^{\circ}$ 078/2000, de 13 de junho do ano 2000, para o empreendimento. Nessa licença, consta a autorização para exercer as atividades específicas de destinação final dos RSU, condicionada ao termo de compromisso de controle e recuperação ambiental previsto no documento. Há de se destacar que nesse período o referido empreendimento encontrava-se fora da área urbana da capital, no sentido de evitar possíveis conflitos e incômodos à população do entorno.

De fato, a autorização de operação do Aterro Sanitário do Município de Boa Vista só foi emitida em 4 de dezembro de 2002, por meio do Documento $n^{\circ} 033 / 2002$, emitido pela Secretaria Municipal de Agricultura, Meio Ambiente e Assuntos Indígenas, com validade de 4 anos. $\mathrm{O}$ empreendimento prevê a disposição e tratamento do lixo domiciliar e hospitalar de Boa Vista, autorizando a Secretaria Municipal de Serviços Públicos e Trânsito a operacionalizar as atividades relativas ao Aterro.

Ocorre que a efetiva operação e gerenciamento dos RSU gerados na capital no período de 2001 a 2013 ficou a cargo da empresa Construtora SOMA Ltda, localizada na Av. Glaycon de Paiva, 2000, no Bairro Mecejana, em Boa Vista, com aproximadamente $60 \%$ da operação do gerenciamento dos RSU, e o restante com as empresas COEMA Ltda, COPAM Ltda e SANEPAV. As exigências e recomendações à empresa SOMA estariam condicionadas à publicidade dos atos praticados, mudança ou acidente na operação da atividade, qualquer impacto negativo ao meio ambiente, controle, fiscalização e monitoramento, tanto do aterro como da área do entorno.

Dados de 2009 mostraram que o Aterro Sanitário de Boa Vista recebeu 30.000 t/mês de resíduos sólidos gerados na capital, sendo 140 t/mês de resíduo de saúde, $0,47 \%$ do total; 10.000 t/mês de resíduo doméstico, equivalente a 33,33\%; e 19.860 t/mês de resíduos inertes, podas de árvores e varrição de logradouros, equivalente a $66,80 \%$ do total.

Para Moreira (2011), o gerenciamento de aterros compreende uma série de procedimentos que vão desde a implantação de políticas de redução do 
volume de material destinado, cobertura do resíduo por solo ou material inerte e de baixa permeabilidade, monitoramento da área de forma direta e indireta, para avaliação da área impactada pelo fluxo de lixiviado, e variações diante das sazonalidades ambientais. Somam-se a essas ações a coleta seletiva, compostagem e rígido controle operacional do material destinado.

\section{Resultados e discussão}

As atividades ilegais de catação e triagem de recicláveis dentro de uma área pertencente ao município geram uma série de questionamentos, uma vez que o acesso ao interior do aterro é feito de forma clandestina, e muitas das vezes burlada através da destruição de elementos de controle do acesso como cercas e portões, bem como conflitos gerados com pessoas imbuídas de fazer segurança do patrimônio municipal.

A situação é preocupante, ocorrem acidentes envolvendo máquinas que removem e espalham os resíduos depositados na grande célula, como no caso de um trabalhador que estava caído no local, teve sérios problemas de saúde após um trator atropelá-lo no período noturno, após ter ingerido bebida alcoólica adormecido no local, contribuindo para o acidente.

A problemática de catação de materiais recicláveis não está por se resolver em curto espaço de tempo como tenta fazer o executivo municipal. Nos meses de novembro e dezembro de 2015, notícia veiculada na imprensa local e que chegou aos envolvidos no problema, seria uma possível retirada dos catadores que atuam dentro do Aterro Sanitário de Boa Vista, bem como a proibição da atividade, sem que houvesse todo um procedimento a ser seguido, no sentido de disponibilizar alternativas de melhoria na condição social e de renda para os que ali atuam.

Colocar os catadores de recicláveis em situação de risco e vulnerabilidade não é novidade no Município de Boa Vista. Funcionou no período de 1994 a 2002, localizado na Zona Oeste de da capital, um local para destinação final dos resíduos sólidos gerados, denominado de Lixeira de Boa Vista, servindo por longo período como fonte de renda e sobrevivência a inúmeros excluídos no Estado, como agricultores oriundos de vicinais do interior do estado, indígenas, desempregados e pessoas que têm sua renda no subemprego.

De acordo com Tonani (2011) a responsabilidade da recuperação da lesão causada ao meio ambiente deve se proceder paralelamente à Educação Ambiental, no sentido de evitar a reincidência. Essa reparação do dano ambiental pode ser mediante a condenação em obrigação de não continuar a prejudicar o meio ambiente e a condenação em obrigação de restaurar o que foi poluído.

A autora ainda destaca que:

Com referência à condenação em obrigação de não fazer, tem-se que a mesma prevê a abstenção das condutas que causaram o dano ambiental, como por exemplo, a determinação para cessação de lançamento de resíduos sólidos em determinado local irregular. A condenação em obrigação de fazer, implica, por exemplo, determinação para remoção dos resíduos sólidos lançados indevidamente (Tonani, 2011).

Em um comparativo entre as situações verificadas no ano de 2002 com a atual situação (Figuras 3a, b e 4a, b, c, d) constata-se que existe pouca diferença do antigo depósito irregular, ou Lixeira Pública de Boa Vista, com a vivenciada no Aterro Sanitário de Boa Vista. 


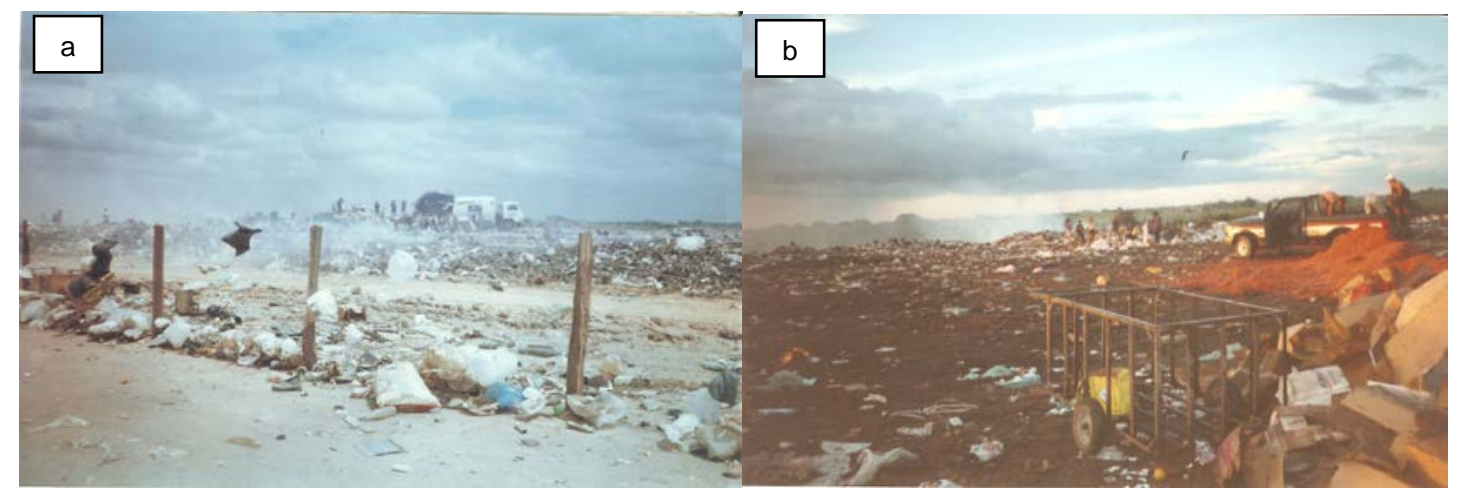

Figura 3. Local de destinação dos RSU do Município de Boa Vista no ano de 2002. Fonte: Reis (2002).

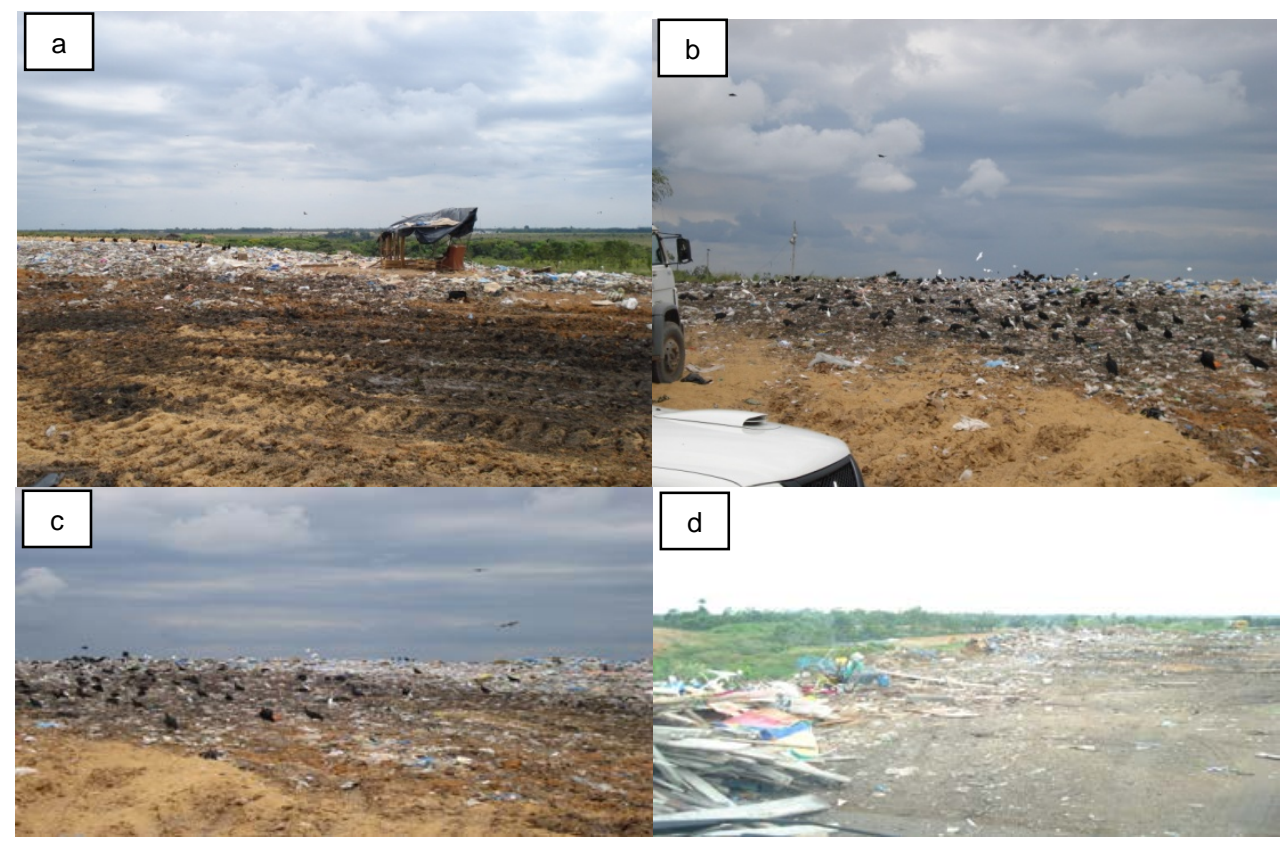

Figura 4. Local de destinação dos RSU do Município de Boa Vista no ano de 2012. Fonte: Roraima (2012).

A atuação do poder público é de fundamental importância na sistemática do que fazer com os RSU provenientes do pósconsumo. Lemos afirma que:

[...] quando os atores responsáveis adotam todas as medidas cabíveis e previstas em legislação específica e mesmo assim o dano é perpetrado, saindo da corriqueira sistemática da responsabilidade preventiva adotada para o sistema tradicional de responsabilização do agente poluidor (Lemos, 2012).
Nesse sentido, a autora destaca as responsabilidades sobre os danos causados ao meio ambiente e enfatiza que:

A responsabilização da cadeia envolvida no pós-consumo se dá de forma preventiva, sem que seja preciso verificar a ocorrência de um dano em seu aspecto naturalístico, ou seja, há responsabilidade por dano futuro.... de modo que é possível, antevendo um dano, a imposição de obrigações de fazer e de não fazer tanto a cadeia produtiva quanto ao consumidor (Lemos, 2012). 
Em relação ao gerenciamento dos RSU e aos seus impactos ambientais e sociais relacionados ao meio desencadeados na área urbana do município, não se vislumbra nenhuma medida no que diz respeito ao passivo ambiental deixado pelo poder público municipal, em relação ao antigo depósito irregular de RSU, que também agride a área do entorno, tanto no aspecto ambiental em função do chorume produzido se dirigir para um curso d'água próximo, como também o social, visto que inúmeras famílias a ocupam com a finalidade de moradia e lazer.

Reafirmando a importância de tornar a reciclagem cada vez mais presente no cotidiano, não só fomentada apenas pelo setor público, mas por todos os segmentos da sociedade civil organizada, Gonçalves afirma que:

[...] o lixo é como um diamante de diversas faces que compõem a sua complexidade na esfera ambiental, social, econômica, psicológica, sanitarista, mitológica e até mesmo afetiva. São faces inseparáveis e precisam ser bem compreendidas de forma integrada por todos os atores do processo, incluindo o indivíduo, para a formação de seu pensamento complexo na busca de um melhor relacionamento com os resíduos gerados pelas sociedades (Gonçalves, 2003).

Entre os anos de 2007 e 2008, o Município tomou a iniciativa de instalar, dentro do Aterro Sanitário, um galpão onde seriam iniciadas atividades de triagem de resíduos sólidos para serem encaminhados a empresas de reciclagem. Conforme relatório encaminhado à Secretaria Municipal de Serviços Públicos - SMSP pela construtora SOMA no ano de 2011, a PMBV cadastrou famílias de catadores da antiga Lixeira e instituiu uma cooperativa denominada Cooperativa dos Amigos Catadores e Recicladores de Resíduos Sólidos - UNIRENDA, cedendo na ocasião um caminhão e um terreno com edificações no Bairro Nova Cidade.

\section{Para Souza:}

No que se refere à reciclagem dos RSU gerados em Boa Vista, a UNIRENDA faz a triagem de parte do lixo gerado no Estado. O papelão compõe $85 \%$ dos materiais separados, seguido do plástico, 13,7\%, e alumínio, 0,14\%, não existindo outra forma de reciclagem do lixo gerado. Nas áreas indígenas, cabe destacar a atuação da Fundação Nacional de Saúde (FUNASA). Nessas áreas, ela é responsável por ações voltadas ao saneamento básico e ambiental (Souza, 2010).

As pessoas envolvidas nas atividades de catação têm origens distintas, oriundas de diversas localidades do estado e do município, excluídas do processo produtivo, do mercado de trabalho e, porque não dizer, da efetiva cidadania. Para Magera (2005):

As cooperativas são compostas por desempregados, muitas vezes, vindos de atividades econômicas não formais, que se deslocam para as áreas urbanas em busca de trabalho, mas que, sem qualquer qualificação para competir no mercado competitivo atual, acabam aceitando qualquer atividade que traga algum tipo de renda necessária a sua sobrevivência. $\mathrm{O}$ ator principal desse cenário é o catador de lixo, que, para tentar se livrar dos atravessadores, forma as chamadas cooperativas de reciclagem (Magera, 2005).

É o que foi feito em Boa Vista, só que pelo poder público municipal, que efetivou a coleta seletiva, destinando todo o material recolhido à referida cooperativa sem custo algum para os cooperados. A decisão equivocada nessas ações foi construir e transferir a cooperativa para dentro da área do aterro.

Sem material para comercializar, diversos integrantes da Cooperativa UNIRENDA voltaram a selecionar resíduos dentro das instalações do Aterro, causando inúmeros problemas em sua operação, onde até boletins de ocorrência foram registrados devido a conflitos entre os catadores e 
funcionários que trabalham diariamente, além de furtos e delitos de diversas ordens.

O número de pessoas envolvidas na atividade de catação de recicláveis para encaminhamento a indústrias de reciclagem em Boa Vista ainda é uma incógnita em função do não cadastramento e controle desses trabalhadores pelos órgãos responsáveis.

Em nível de Brasil, estima-se que cerca de 800 mil pessoas sobrevivem da catação de materiais reciclados, obtendo renda média mensal de 1 a 1,5 salário mínimo. Um dos principais resíduos com maior incidência na catação é o alumínio, que reforça a vocação da sua indústria para a sustentabilidade em termos econômicos, sociais e ambientais, podendo ser reciclado infinitas vezes, sem perder suas características no processo de reaproveitamento, diferenciando-o de outros materiais como as pet e papelão de forma geral (Ribeiro e Morelli, 2009).

Outro problema identificado com a presença de catadores dentro do aterro se refere a constantes incêndios, desencadeados muitas das vezes pelos próprios catadores. A existência de fogo no aterro dificulta toda a atividade ali desenvolvida e coloca em situação vulnerável os trabalhadores, os catodores e os equipamentos que ali operam. Tem-se registro de incêndios de grandes proporções nos meses de abril e maio do ano de 2011, período de estiagem em Roraima, quando ficaram impossibilitados de adentrarem o aterro diversos caminhões com galhadas e entulhos, necessitando a transferência para outra área para sua disposição final.

O capítulo VI, da Lei $\mathrm{n}^{\circ}$ $12.305 / 2010$, que trata das proibições, em seu art. 48, I, II, III, IV e V, diz:

Art. 48. São proibidas, nas áreas de disposição final de resíduos ou rejeitos, as seguintes atividades:

I - utilização dos rejeitos dispostos como alimentação;

II - catação, observado o disposto no inciso $\mathrm{V}$ do art. 17;

III - criação de animais domésticos;

IV - fixação de habitações temporárias ou permanentes;
V - outras atividades vedadas pelo poder público.

Mas o que se constata no aterro sanitário é justamente o contrário do que prevê a Lei $\mathrm{n}^{0} 12.305 / 2010$, onde a presença de catadores de matérias recicláveis é constante e ininterrupta como também a fixação de abrigos ou moradias temporárias utilizadas por estes catadores.

Mas em Boa Vista, após a implementação da coleta seletiva no Município, que deveria ser uma solução para inúmeras pessoas que tiram o seu sustento diariamente, na verdade se transformou em um problema social de grande magnitude. Sucessivamente o jornalista Amilcar Júnior (2013) enfatiza, em sua coluna de um jornal local, que catadores de lixo voltam a ocupar o Aterro Sanitário e montam barracos, inclusive morando no local. É possível ver algumas casas improvisadas com papelão e lonas, o que indica que lá existem pessoas morando, disputando espaço com urubus.

Essa situação se agrava uma vez que as reivindicações dos atores envolvidos não têm chamado a atenção dos gestores, como diz Stroh (2009):

Quanto à inclusão social dos catadores, que trabalham em áreas de disposição final de RSU, estão presentes como uma expressão particular de um movimento social de âmbito nacional denominado MNCR, que luta contra a exclusão social de um contingente considerável de seres humanos. Em nível de Brasil, esses trabalhadores vêm se fortalecendo e a sua mobilização e organização se torna cada vez mais relevante na busca da cidadania plena (Stroh, 2009).

Esses trabalhos deveriam estar inseridos na lógica e mecanismo de redução de impactos ambientais, pois são considerados como empregos verdes. Por empregos verdes, Compagnoni et al. (2012) esclarecem ser um trabalho formal em atividades que contribuem significativamente para preservar ou restaurar a qualidade ambiental. Reduz impactos ambientais, ajuda a proteger a 
biodiversidade e os ecossistemas, evita formas de desperdício e poluição na direção da sustentabilidade e dá oportunidade para que pessoas sejam inseridas no mercado de trabalho.

Uma proposta a ser levada em discussão para os agentes públicos e sociedade envolvida no processo, teria como parâmetro para encerramento do lixão do Município de Boa Vista, o Guia de Atuação Ministerial de 2014 (Tabela 1).
Esse documento explicita claramente as prerrogativas a serem seguidas no que diz respeito aos catadores que, dentre outras ações, condicionaria a retirada desses a partir de ações como a inclusão social e produtiva dos trabalhadores envolvidos na coleta e triagem de materiais recicláveis. $\mathrm{O}$ documento salienta ainda a visitação para verificação nos locais de coletas, analisando a situação dos catadores ali presentes.

Tabela 1. Ações necessárias para a inclusão social dos catadores de recicláveis.

\begin{tabular}{|l|l|}
\hline $\mathbf{N}^{\mathbf{0}}$ & \multicolumn{1}{c|}{ AÇÕES } \\
\hline 01 & Identificar o número de catadores e catadoras que trabalham no lixão; \\
\hline 02 & Verificar a presença de crianças e adolescentes; \\
\hline 03 & Verificar a existência de moradias permanentes de catadores na área do lixão; \\
\hline 04 & Verificar a presença de “atravessador” ou “gato”; \\
\hline 05 & Verificar se os catadores encontrados no lixão se estão cadastrados no Cadastro Único (CadÚnico); \\
\hline 06 & $\begin{array}{l}\text { Verificar se os planos municipais contemplam ações obrigatórias como: diagnóstico dos } \\
\text { resíduos, contratação das associações e cooperativas de catadores, coleta seletiva, compostagem, } \\
\text { destinação dos resíduos inertes; educação ambiental, encerramento do lixão, recuperação da área } \\
\text { degradada, etc.; }\end{array}$ \\
\hline 07 & $\begin{array}{l}\text { Verificar a existência de diagnóstico sobre a situação social dos catadores e catadoras, bem como de } \\
\text { suas famílias; }\end{array}$ \\
\hline 08 & $\begin{array}{l}\text { Verificar se há ou não contratação e remuneração às associações e cooperativas pelos serviços } \\
\text { prestados ao Município; }\end{array}$ \\
\hline 09 & Verificar a existência de análise gravimétrica e volumétrica (composição e volume); \\
\hline 10 & Verificar a existência de local apropriado para os catadores realizarem suas atividades; \\
\hline 11 & $\begin{array}{l}\text { Verificar a existência de veículos apropriados (como caminhões) para a realização da coleta } \\
\text { seletiva; }\end{array}$ \\
\hline 12 & $\begin{array}{l}\text { Verificar se há organização dos catadores, em associações ou cooperativas, e se a documentação se } \\
\text { encontra regular (atas, estatuto, controle fiscal e financeiro, etc.). }\end{array}$ \\
\hline 13 & $\begin{array}{l}\text { Verificar o índice de analfabetos ou analfabetos funcionais dentre os catadores, bem como } \\
\text { deficiência na formação profissional; }\end{array}$ \\
\hline 14 & $\begin{array}{l}\text { Verificar a existência de acompanhamento da saúde das famílias que sobrevivem da coleta de } \\
\text { materiais recicláveis; }\end{array}$ \\
\hline 15 & Verificar a exploração do trabalho de crianças e adolescentes. \\
\hline
\end{tabular}

Fonte: Adaptado de Brasil (2014). Guia de Atuação Ministerial: Encerramento dos lixões e a inclusão social e produtiva das catadoras e catadores de materiais recicláveis.

Essas ações propostas serviriam para mitigar a problemática do pósfechamento do Aterro Sanitário de Boa Vista para os catadores de recicláveis e sua efetivação em um verdadeiro local para disposição final de RSU gerados, de forma a contemplar todos os protocolos ambientais, sociais e econômicos. Por conseguinte, a disseminação das propostas apresentadas serviria para todo o Estado de Roraima, uma vez que os órgãos de controle do Estado informam que apenas o Município de Mucajaí teve o plano municipal de RSU aprovado. Com relação à construção de aterro sanitário destaca-se o Município de Normandia, cabendo ao restante dos municípios do Estado a efetivação destes empreendimentos. 


\section{Considerações finais}

Após as inúmeras variáveis e condicionantes que estão intimamente ligadas à situação dos catadores de materiais recicláveis que atuam no Aterro Sanitário de Boa Vista, surgem as indagações do que seria necessário para mitigar a problemática e quais os passos a seguir por todos os interessados no problema.

No sentido de tentar eliminar o problema, faz-se inconteste uma série de medidas que vão desde a elaboração e implantação do chamado Plano Municipal de Resíduos Sólidos necessários para a eliminação dos chamados lixões. Esses documentos devem sem elaborados com ampla participação da sociedade como um todo. Entende-se que as medidas propostas pelo Guia de Atuação Ministerial para o encerramento de lixões, enfatizadas no quadro acima, contemplam, quase em sua totalidade, as inúmeras medidas necessárias para a inclusão desses trabalhadores em uma melhor condição social.

Por fim, há que se destacar o papel relevante para a sociedade do Ministério Público do Trabalho em Roraima que cumpre seu papel de mediador nos conflitos resultantes das atividades de catação, e do Fórum Lixo e Cidadania, que, nesse contexto de conflito entre os catadores e o executivo municipal, vem sendo um espaço de discussão da problemática, buscando soluções que possam trazer benefícios para os inúmeros catadores.

$\begin{array}{ccr}\text { Nesse } & \text { espaço } & \text { democrático de } \\ \text { proposituras, } & \text { estão } & \text { envolvidos }\end{array}$ representantes e gestores públicos, iniciativa privada, bem como representantes das organizações de catadores como cooperativas e associações na busca de medidas de curto, médio e longo prazo, e que a problemática da catação de recicláveis no Município de Boa Vista seja feita de forma que respeite a equidade, tanto ambiental como social.

\section{Declaração de conflito de interesses}

Os autores declaram não haver conflitos de interesses.

\section{Referências}

ABNT - Associação Brasileira de Normas Técnicas. NBR 8418: Apresentação de projetos de aterros de resíduos industriais perigosos Procedimento. Rio de Janeiro: ABNT, 1984.

ABNT - Associação Brasileira de Normas Técnicas. NBR 8849: Apresentação de projetos de aterros controlados de resíduos sólidos urbanos - Procedimento. Rio de Janeiro: ABNT, 1985.

ABNT - Associação Brasileira de Normas Técnicas. NBR 10.004: Resíduos sólidos Classificação. Rio de Janeiro: ABNT, 2004.

Amilcar Júnior. Catadores de lixo voltam a ocupar aterro sanitário e montam barracos. Folha de Boa Vista, 26/03/2013. Disponível em: $<$ http://www.folhabv.com.br/noticia.php?id=148 750>. Acesso em: 07 maio 2013.

Barbosa, R. I.; Xaud, H. A. M.; Costa e Sousa, J. M. Savanas de Roraima: etnoecologia, biodiversidade e potencialidades agrossilvipastoris. 1 ed. Boa Vista: FEMACT, 2005.

Brasil. Guia de atuação ministerial: encerramento dos lixões e inclusão social e produtiva de catadoras e catadores de materiais recicláveis. Brasília: Conselho Nacional do Ministério Público, 2014. Disponível em: $<$ http://www.cnmp.mp.br/portal/images/Livro_ Catadores_WEB.pdf $>$. Acesso em: 01 mar. 2016.

Brasil. Leis, decretos etc. Lei $\mathbf{n}^{0} \mathbf{1 0 . 2 5 7}$, de 10 de julho de 2001. Regulamenta os arts. 182 e 183 da Constituição Federal, estabelece diretrizes gerais da política urbana e dá outras providências. Disponível em: <http://www.planalto.gov.br/ccivil_03/leis/LEIS _2001/L10257.htm>. Acesso em: 29 jul. 2012.

Brasil. Leis, decretos etc. Lei ${ }^{0}$ 12.305, de 2 de agosto de 2010. Institui a Política Nacional de Resíduos Sólidos; altera a Lei no 9.605, de 12 de fevereiro de 1998; e dá outras providências. Disponível em: <http://www.planalto.gov.br/ ccivil_03/_ato2007-2010/2010/lei/112305.htm>. Acesso em: 29 jul. 2012.

Compagnoni, R. L.; Chemin, B. F.; Turatti, L.; Calderan, T. B.; Konrad, O. Empregos verdes como mecanismo de redução de impactos ambientais. Âmbito Jurídico, Rio Grande, XV, n. 106, nov 2012. Disponível em: <http://www.ambitojuridico.com.br/site/?n_link =revista_artigos_leitura\&artigo_id=12423>.

Acesso em: 08 jun. 2013.

Corrêa, R. L. Espaço, um conceito - chave da Geografia. In: Castro, I. E.; Gomes, P. C. C.; 
Corrêa, R. L. Geografia: conceitos e temas. 2. ed. Rio de Janeiro: Bertrand Brasil, 2000.

Farias, M. V. A.; Veras, A. S. S.; Paixão, S. A. Degradação do corpo hídrico no urbano em Boa Vista-RR. Textos e Debates, v. 19, p. 121-141, 2013.

Gil, A. C. Como elaborar projetos de pesquisa. 4 ed. São Paulo: Atlas, 2002.

Gonçalves, P. A reciclagem integradora dos aspectos ambientais, sociais e econômicos. 1 ed. Rio de Janeiro: DP\&A, Fase, 2003.

IBGE - Instituto Brasileiro de Geografia e Estatística. Pesquisa Nacional de Saneamento Básico, PNSB - 2008. Rio de Janeiro: IBGE; 2010. Disponível em: <http://www.ibge.gov.br/ home/estatistica/populacao/condicaodevida/pns b2008/PNSB_2008.pdf>. Acesso em: 29 jul. 2012.

IBGE - Instituto Brasileiro de Geografia e Estatística. 2015. Disponível em: $<$ http://www.ibge.gov.br/cidadesat/perfil.php>. Acesso em: 29 fev. 2016.

Lemos, P. F. I. Resíduos sólidos e responsabilidade civil pós-consumo. 2 ed. São Paulo: Revista dos Tribunais, 2012.

Magera, M. Os empresários do lixo: um paradoxo da modernidade. 2 ed. Campinas: Átomo, 2005.

Moraes, A. C. R. Geografia: pequena história crítica. 19. ed. São Paulo: Annablume, 2003.

Moreira, C. A.; Braga, A. C.; Hansen, M. A. F. Estimativa do tempo de produção de chorume em aterro controlado por meio de medidas de resistividade elétrica. Revista Brasileira de Geociências, v. 41, n. 3, p. 549-557, 2011.
Disponível em: <http://sbg.sitepessoal.com/ bjg/2011/n.3/o.pdf>. Acesso em: 13 ago. 2012.

Ribeiro, D. V.; Morelli, M. R. Resíduos sólidos: problema ou oportunidade? 1 ed. Rio de Janeiro: Interciência, 2009.

Roraima. Secretaria Estadual de Planejamento e Desenvolvimento de Roraima. Conjuntura e oportunidades. Boa Vista: SEPSR, 2009.

Roraima. Secretaria de Estado do Planejamento e Desenvolvimento de Roraima. Produto Interno Bruto Estadual e Municipal. 5 ed. Boa Vista: SEPSR, 2009.

Roraima. Ministério Público do Estado de Roraima. Promotoria de Justiça de Defesa do Meio Ambiente e Patrimônio Histórico. Boa Vista: MPRR, 2012.

Silva, D. F.; Matos, A. T.; Pereira, O. G.; Cecon, P. R.; Moreira, D. A. Disponibilidade de sódio em solo com capim tifton e aplicação de percolado de resíduo sólido. Revista Brasileira de Engenharia Agrícola e Ambiental, v. 14, n. $10, \quad$ p. 1094-1100, 2010. http://dx.doi.org/10.1590/S1415-43662010001000011

Souza, V.; Tavares Júnior, S. S.; Oliveira, R. S. Atlas dos igarapés urbanos de Boa Vista Roraima. 1 ed. Boa Vista: Editora da UFRR, 2010. v. 1.

Stroh, P. Y. (Org.). Cidade, lixo e cidadania. 1 ed. Maceió: UFAL, 2009.

Tonani, P. Responsabilidade decorrente da poluição por resíduos sólidos: de acordo com a Lei 12.305/2010 - Institui a Política Nacional de Resíduos Sólidos. 2 ed. São Paulo: Método, 2011.

Informação da Licença: Este é um artigo Open Access distribuído sob os termos da Licença Creative Commons AtribuiçãoSemDerivações-SemDerivados, que permite o download do trabalho e o compartilhamento desde que seja atribuído o devido crédito, mas sem que possa ser alterado de nenhuma forma ou utilizá-los para fins comerciais. 